\title{
Down Syndrome (Trisomy 21)
}

National Human Genome Research Institute (NHGRI)

\section{Source}

National Human Genome Research Institute (NHGRI). Down Syndrome (Trisomy 21).

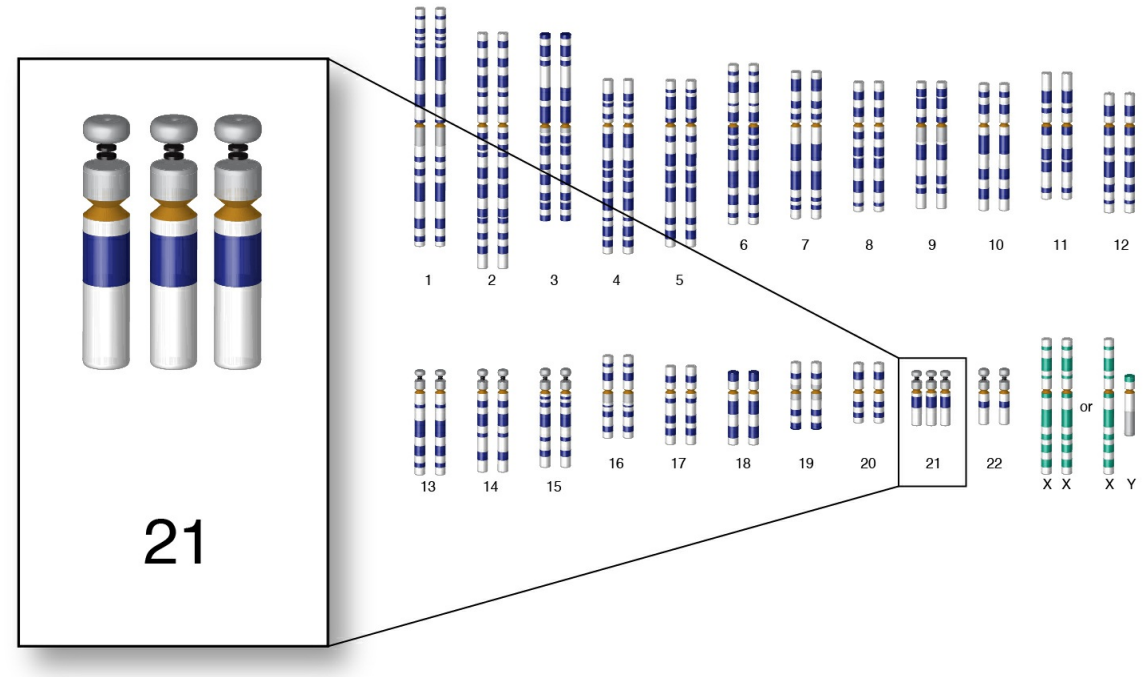

Down syndrome is a genetic disease resulting from a chromosomal abnormality. An individual with Down syndrome inherits all or part of an extra copy of Chromosome 21. Symptoms associated with the syndrome include mental retardation, distinctive facial characteristics, and increased risk for heart defects and digestive problems, which can range from mild to severe. The risk of having a child with Down syndrome rises with the mother's age at the time of conception. 